\title{
KONSEP ADAB PENUNTUT ILMU MENURUT IBN ABD AL-BARR DAN RELEVANSINYA DENGAN PENDIDIKAN NASIONAL
}

\author{
MUSLIM, ABDUL HAYYIE AL-KATTĀNI, WIDO SUPRAHA
}

\begin{abstract}
Muslim Universitas Ibn Khaldun

Dunia pendidikan saat ini cukup memprihatinkan. Adab Islami yang telah diwariskan oleh para leluhur tidak mendapatkan porsi yang cukup untuk diajarkan dan Abdul Hayyie Al-Kattani Universitas Ibn Khaldun

Wido Supraha Universitas Ibn Khaldun ditanamkan kepada peserta didik. Konsekwensinya terjadilah fenomena gunung es, hilangnya adab dari para penuntut ilmu. Dua tahun terakhir beragam kasus kriminal memuncak dan menuai respon para pakar dan praktisi pendidikan. Di antaranya: kekerasan seorang guru terhadap murid yang berakibat anak itu menyeret sang Email abdzmuslim@gmail.com guru ke meja hijau, seorang murid memukul guru, seorang mahasiswa membunuh dosennya sendiri, dan berbagai masalah lainnya. Tujuan dari penelitian ini untuk mengetahui konsep adab penuntut ilmu menurut Ibn Abd al-Barr dan relevansinya dengan pendidikan nasional. Penelitian ini menjadi urgent dalam upaya meningkatkan kualitas pendidikan membentuk manusia berkarakter dan beradab yang kian hari semakin carut-marut. Metode penelitian menggunakan pendekatan sejarah (historiografi) dan studi pustaka (library research). Hasil penelitian menunjukkan adanya relevansi konsep adab beliau dengan pendidikan nasional. Melalui karyakaryanya itu ia telah menuangkan gagasan yang senantiasa relevan sepanjang zaman. Sehingga sumbangsihnya bagi dunia Islam turut mewarnai peradaban Islam di belahan benua Eropa, Andalusia dan lainnya. Al-Quran dan sunnah serta perkataan (aqwāl) para ulama salaf memperkokoh bangunan konsep adab yang beliau gagas sehingga meninggikan peradaban Islam di masa silam dan masa yang akan datang.
\end{abstract}

Keywords : Adab, Akhlak, Pendidikan Nasional 
Konsep Adab Penuntut IImu:...(Muslim)

\section{A. Pendahuluan}

Seseorang yang memiliki segudang ilmu, wawasan luas, dan akal yang cerdas, semua itu tidaklah berarti baginya jika tanpa dihiasi dengan adab Islami. Menurut Syaikh al-Utsaimin (1434: 7), seorang ulama Saudi yang tergabung dalam organisasi para ulama besar (Hai’ah Kibāri al-Ulamā) sejak 1417 H., "Apabila penuntut ilmu tidak menghiasi dirinya dengan budi pekerti yang baik (akhlak al-fādhilah), meskipun ia menuntut ilmu, maka ilmunya itu tidak memberikan manfaat".

Bangsa Indonesia saat ini mencapai puncak dalam menghadapi berbagai permasalahan pendidikan, khususnya kemerosotan akhlak dan hilangnya adab (istilah yang populer menurut al-Attas (1993:105) adalah “The loss of adab”). Di antara sekian banyak kasus yang terjadi adalah kekerasan seksual pada anak baik berupa homoseks (pedofilia) seperti data yang disebutkan oleh Adian Husaini (2015: 4-27), kasus perkosaan di kalangan pelajar yang baru saja menggegerkan dunia pendidikan sehingga menjadi pukulan keras bagi para pemangku kebijakan (Hasanul Rizqa: 2017), masih semarak tawuran antar pelajar bahkan di tingkat mahasiswa (Abdul Haq: 2017), bahkan pada bulan November 2016 lalu siswa SD akan menyerang SD lain di Semarang (Angling Adhitya Purbaya: 2017), dan pembunuhan seorang dosen oleh mahasiswa (Indra Fauzi: 2017).

Berbagai permasalahan di atas disadari oleh masyarakat bahwa hal itu merupakan fenomena gunung es. Adian Husaini (2012: ix) mengungkapkan, "Pendidikan bukan hanya untuk menghasilkan manusia cerdas, tapi manusia yang berkarakter. Justru karakterlah yang dipandang lebih penting dalam kehidupan manusia." Oleh karena itu, langkah pemerintah sudah tepat dalam menjadikan pendidikan karakter dan adab ini menjadi tujuan pendidikan pemerintah yang tertuang dalam Undang-undang Sistem Pendidikan Nasional (SISDIKNAS) no. 20 tahun 2003.

Sementara itu, di belahan benua Eropa, Andalusia (Spanyol) yang menjadi pusat peradaban pada masa Khilafah Bani Umayyah II yang didirikan oleh Abdu ar-Rahmān ibn Muawiyah ibn Hisyam ibn Abdi al-Malik ibn Marwan (As-Suyūthi: 2007, 461), hiduplah seorang ulama besar yang memiliki berbagai karya fenomenal di sana, terutama dalam pembahasan adab 
yang berjilid-jilid dan komprehensif. Beliau adalah al-Imam Ibn Abd al-Barr sang tokoh yang patut untuk ditiru dan layak diteladani.

Berdasarkan hal-hal tersebut di atas, kami ingin meneliti pemikiran lbn Abd al-Barr dengan judul “Konsep Adab Penuntut Ilmu Menurut Ibn Abd Al-Barr dan Relevansinya dengan Pendidikan Nasional." Belum banyak penelitian yang menguraikan pemikiran beliau khususnya berkaitan dengan pendidikan karakter dan adab Islami. Beliau termasuk ulama yang memberikan kontribusi besar bagi generasi berikutnya dalam meletakkan disiplin ilmu adab Islami.

\section{B. Metode Penelitian}

Pemikiran tokoh yang diteliti hidup sepuluh abad lalu. Oleh karena itu, pendekatan yang ditempuh dalam penelitian ini adalah dengan pendekatan sejarah (historiografi) dan studi pustaka (library research). Menurut Langgulung (1988: 2), "Pendekatan pertama untuk membicarakan pendidikan Islam lebih mudah sebab cukup banyak peninggalan dan karangan yang dapat dibaca melalui buku-buku riwayat hidup, ilmu kalam, ilmu fikih, bebagai referensi mengenai sejarah Islam semenjak bangkitnya Islam empat belas abad yang lalu sampai sekarang."

Data yang terkumpul berupa data primer dan sekunder. Data primer adalah data yang langsung dihimpun dari karya-karya Ibn Abd al-Barr, sedangkan data sekunder adalah data yang dikumpulkan oleh peneliti lainnya. Data primer yang digunakan adalah: 1) kitab Jāmi Bayāni al-Ilmi, ensiklopedi adab (dua jilid); 2) Bahjatu al-Muqtabis wa Ansu al-Mujālis bimā Yajrī, kitab sastra yang mengajarkan adab bermuamalah/interaksi sosial (dua jilid); 3) Adab al-Mujālasā wa Hamdu al-Lisān, etika bermuamalah dan menjaga lisan.

\section{Hasil dan Pembahasan}

1. Ibn Abd Al-Barr (368-463 H./9781070 M.), Sang Pemilik Mutiara Adab Islami

Menurut ahli kirtik hadits dan sejarawan Islam, al-Imam adz-Dzahabi rahimahullāh (w. 748 H.), nama lengkap Ibn Abd al-Barr adalah: Yūsuf ibn Abdillāh ibn Muhammad ibn Abd alBarr ibn Āshim an-Namari al-Andalusi al-Qurthubi al-Maliki, penulis kitab yang sangat banyak (adz-Dzahabi : 2011, jilid 18, 153-154). Pen-tahqia kitab Siyar (syaikh Syuaib al-Arnaūt) 
Konsep Adab Penuntut IImu:...(Muslim)

menambahkan, "Beliau dilahirkan di tengah-tengah suku an-Namir ibn Qūsith sebuah suku (Arab) besar yang terkenal. Sebagian ulama ada yang menyebutkan bahwa beliau dilahirkan pada bulan Jumāda al-Ūlā pada tahun 368 H." Amīn Abū Lāwīi (Ushūl at-Tarbiyah alIslāmiyah: 284) menyebutkan, "Ibn Abd al-Barr dilahirkan pada hari Jumat (pekan) ke lima di bulan Rabīul Akhir ketika imam sedang berkhutbah tahun 368 H."

Ibn Abd al-Barr tumbuh besar di kota Qurthubah (Cordova) ibu kota alkhilafah al-Islāmiyah Ban̄i Umayyah Andalusia ketika itu dan sekaligus kota ilmu (Amīn Abū Lāwī: 284). la seringkali berpidah ke belahan Timur dan Barat di negerinya itu. la pernah tinggal di Daniah, Valencia, Syāthibah, dan pernah pula menetap di Usybūnah, ibu kota Fortugal sekarang (Adz-Dzahabi: 156). la mendengar (belajar) hadits-hadits Sunan Abi Dawud, al-Musnad karya Imam Ahmad ibn Hambal (w. 241 H.)

Abdu ar-Rahmān an-Nahlāwi (1986: 9) menginformasikan bahwa Ibn Abdi al-Barr mempelajari ilmu fiqih dan menyelami seluk beluknya (bertafaqquh). Beliau bermulazamah kepada ahli fiqih yang dimuliakan, mufti yang diutamakan dari fatwa siapapun di
Qurthubah, Abu Umar Ahmad ibn Abd al-Malik al-Isybīīi (w. 426 H.) dan seorang ulama yang hăfizh, kuat hafalannya (mutqin) dan ālim serta penulis biografi para ulama Andalusia, Abu al-Walīd ibn Faradhi (w. 400 H.). An-Nahlāwi (1986: 9) menyatakan pula bahwa darinyalah ia menimba ilmu adab dan hadits. Beberapa ulama yang cukup terkenal dan tercatat sebagai muridnya adalah: Ibn Hazm al-Andalusī (w. 456 H.), Al-Humaidi (w. 488 H.), Abu Ali al-Chassānī (427-498 H./w. 1104 M.) dan para ulama lainnya.

Adz-Dzahabi (1405: jilid 2, 316 dan 2011: 159) menuturkan, Ibn Abd alBarr menghadap Sang Pencipta pada akhir bulan Rabiul Akhir dalam usia 95 tahun 5 hari. Kata Abu Dawud al-Muqri, beliau wafat pada malam Jumat tahun 463 H./1070 M di kota Syāthibah.

2. Karya Beliau

Laporan dari al-Imām al-Humaidi (1410: 587-588) tentang karya-karya beliau (14 judul buku pertama dari

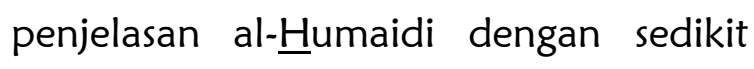
update informasi):

a. Kitab at-Tamhīd Limā fi alMuwathai min al-Ma'ānī wa alAsānīd; 
b. Al-lstiāb fi Marifati Asmāi alAshāb 12 jilid;

c. Kitab Jāmi Bayāni al-llmi wa Fadhlihi, enam jilid dan Adab alMujālis wa Hamdu al-Lisān. Menurut Abu Lāwī (287), kitab ini termasuk kategori kitab tarbiyah, akhlak, dan adab. Kitab ini penting untuk dipelajari oleh para penuntut ilmu, para guru, dan masyarakat pada umumnya karena berisi perkara pokok ilmu, adab dan akhlak (Abū Asybāl: $1414,21)$;

d. Bidang sejarah: kitāb Ad-Durār fi Ikhtishār al-Maghāzì wa as-Siyar, al-Intiqā fi Fadhāili ats-Tsalātsah al-Fuqahā (Malik, Syafii, dan Abu Hanifah), al-Inbāh ala Qabāili arRuwāt, ad-Durar fi Ikhtishāri alMaghāzī wa as-Siyar, al-Qashdhu wa al-Umām fi Marifati Ansāb alArab wa al-Aja;

e. Di bidang aqidah: Asy-Syawahīd fi Itsbāt Khabar al-Wāhid (penetapan sahnya hadits Ahad), satu jilid; dan di bidang-bidang ilmu lainnya yang mencapai lebih dari 50 judul buku seperti atTaqash-shi limā $f \bar{c}$ al-Muwatha

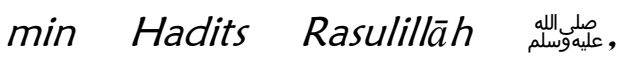
Akhbār Aimmah al-Amshār, al-
Bayān an Tilāwati al-Qurān, alIktafā fi Qirāati Nāfi wa Abi Amr ibn al-Alā bi Attaujĭh mā ikhtalafā fihi, at-Tajwid, dan banyak lagi yang lainnya.

Amīn Abū Lāwī, guru besar di salah satu universitas kota Aman Yordania memberikan apresiasi terhadap karya-karya Ibn Abd al-Barr dengan memasukkan beliau sebagai figur tokoh pendidikan di antara deretan tokoh-tokoh pendidikan di kitāb Ushūl at-Tarbiyah al-Islāmiyah, (287). la mengatakan bahwa karya beliau yang paling terkenal, Jāmi Bayāni al-Ilmi wa Fadhlihi termasuk buku pendidikan jiwa dalam turats Islami yang bagus. Buku tersebut merupakan buku pendidikan yang membahas $a d a b$ ilmu dan talim serta menjelaskan cakupan keduanya secara global.

3. Pemikiran Ibn Abd Al-Barr Tentang Pendidikan dan Adab Penuntut IImu

Selama proses penelusuran beberapa karya Ibn Abd al-Barr, tidak ditemukan penjelasan konsep pendidikan maupun adab secara definitif. Barangkali ketika itu memang istilah pendidikan dan adab sudah maruf sehingga konsep yang digagasnya lebih 
Konsep Adab Penuntut IImu:...(Muslim)

menitikberatkan pada panduan praktis dan prinsip-prinsip dalam pendidikan adab. Karena panduan praktis dari konsep yang beliau sebutkan sangat banyak, maka penulis hanya menyebutkan sebagiannya saja yang sudah di-tahqī oleh Abū Asybāl agar tidak terlalu meluas. Selain itu, sebagian riwayat yang beliau sebutkan merupakan riwayat yang dhaîf, sebagiannya dhaîf jiddan bahkan terindikasi palsu (maudhū).

Meskipun demikian, riwayatriwayat tersebut terkadang bisa saling menguatkan (memiliki mutābaah) sebagaimana telah maklum di kalangan ahli ilmu hadits. Banyaknya riwayat yang dhaîf, sebagiannya dhaîf jiddan dan palsu, maka sebagai kehati-hatian sebagaimana yang telah dilakukan oleh para salaf seperti yang diceritakan oleh syaikh Muhammad Shafwat Nūr ad-Dīn, Direktur Jamaah Anshāru as-Sunnah alMuhammadiyah, beberapa contoh adab yang dicantumkan sudah dinyatakan shahih oleh pen-tahqīq (Abū Asybāl: 1996, 6).

\section{Prinsip-Prinsip Tarbiyah}

Ibn Abd al-Barr tidak banyak memberikan komentar ataupun uraian pada konsep-konsep yang beliau sodorkan. Karena kepiawaiannya dalam bidang hadits dan atsar, maka beliau lebih cenderung untuk mengutipkan riwayat-riwayat yang bermuatan prinsip-prinsip tarbiyah untuk para guru dan murid. Abū Asybal (1996: 21-36) merangkumnya sebagai berikut (dengan beberapa tambahan referensi):

a. Wajib mengajarkan ilmu dan haram menyembunyikannya (Abū Asybal: 1996, 25).

b. Wajib menuntut ilmu berdasarkan hadits riwayat Anas ibn Mālik (Ibn Abd al-Barr: 1435, jilid 1, hlm. 22, 69, 72, 73, 84, dan 90).

c. Niat yang ikhlas dalam menuntut ilmu. An-Nahlāwī (2003: 41) mengatakan, “... Niat adalah maksud yang dituju oleh Sang guru dan murid di balik usahanya itu." Al-Ustadz Yazīd ibn Abd al-Qadīr Jawaz (2012: 111) mengatakan, "Niat adalah dasar dan rukun amal. Apabila niat itu salah dan rusak, maka amal yang dilakukannya pun ikut salah dan rusak sebesar salah dan rusaknya niat."

Ibn Abd al-Barr menyebutkan hadits riwayat dari Jābir ibn Abdillah:

Janganlah kalian belajar ilmu untuk berbangga diri di hadapan para ulama, jangan pula belajar ilmu untuk mendebat orang-orang 
bodoh, jangan pula sekedar untuk menguasai majelis! Orang yang melakukan perbuatan demikian lebih pantas tempatnya di neraka. (H.R. Ibn Mājah no. 254; Ibn Hiban: Shahīhah, no. 77, dan yang lainnya dalam Ibn Abd al-Barr: $1435,524)$

Ibn Mubārak sang ahli zuhud yang hidup antara 118-181 H. (AnNahlāwī: 1986, 44-45) mengatakan, "Langkah awal dari menuntut ilmu adalah niat (yang benar)."

d. Menyelenggarakan pendidikan gratis berdasarkan riwayat Abū al-Āliyah (Abū Asybal: 1435, 25).

e. Amanah ilmiah dan meneliti yang shahīh (An-Nahlāwī: 1986, 59-60).

f. Memperbaiki kekeliruan dan kesalahan (Abū Asybal: 1435, 26).

5. Adab Penuntut Ilmu; Bagi Guru dan Murid

Ibn Abd al-Barr (1435: 164) mencantumkan riwayat Shafwān lbn Assāl yang menunjukkan bahwa hendaknya Sang guru memberikan sambutan yang hangat kepada muridmuridnya:

$$
\text { (مَزْحًَا بِطَالِبِ الْعِلْم ،....) }
$$

"Selamat datang para penuntut ilmu...."

a. Bersikap tawadhu dan tidak sombong (Ibn Abd al-Barr: 1435, 26-27).

b. Menyambut penuntut ilmu dengan ramah dan mengajarkan (ilmu) serta bersikap santun terhadap mereka (Ibn Abd al-Barr: 1435, 27-28 dan 469).

c. Memuliakan guru dan beradab terhadapnya (Abū Asybāl: 1996, 31 32 dan Ibn Abd al-Barr: 1435, 28).

d. Adab seorang guru (Abū Asybāl: 1996, 28-29);

1) Hendaknya seorang guru memiliki wibawa (haibah), bersikap tenang, dan tidak mudah marah.

2) Tidak banyak bersenda gurau, tidur, dan tidak banyak tertawa.

3) Seorang guru hendaknya menghiasi dirinya dengan adab Islami.

4) Wajib bagi seorang yang berilmu untuk tidak berdebat dengan orang bodoh (jāhil).

5) Sedikit bicara

6) Diam dari sesuatu yang tidak diketahuinya dan tidak tergesagesa menjawab pertanyaan (sampai ia benar-benar memahami apa yang ditanyakan). 
7) Menjawab "tidak tahu" jika memang tidak mengetahui sesuatu yang ditanyakan.

8) Tidak tergesa-gesa menjawab sampai memahami dengan baik pertanyaan dari penanya.

\section{Tujuan Pendidikan Adab}

Pernyataan Ibn Abd al-Barr terhadap hadits Jābir (H.R. Ibn Mājah no. 254, Ibn Hiban dalam Shahīhah no. 77, dan yang lainnya) menunjukkan tujuan dari menuntut ilmu dan pendidikan adab adalah untuk memperoleh kebaikan. Hal ini sesuai pula dengan pernyataan Adian Husaini (2012: 50) bahwa dunia pendidikan kita sudah sepatutnya menekankan proses ta'dib. la pun menyatakan, "Islam memandang kedudukan ilmu sangatlah penting, sebagai jalan mengenal Allah dan beribadah kepada-Nya. Ilmu juga satu-satunya jalan meraih adab."

Ibn Abd al-Barr (1435: 603-610) senantiasa melandaskan pendidikan adab dengan sumber-sumber utama hukum Islam dan berdasarkan ilmu riwayat-riwayat dari generasi salaf (atsar). Landasan ini yang menopang konsep beliau agar tetap menjaga orisinalitas melalui adanya atsar yang datang dari para ulama.
7. Kurikulum dan Evaluasi Pendidikan Adab

Sebagai sebuah perangkat pendidikan untuk mencapai tujuan, kurikulum yang diterapkan oleh lbn Abd al-Barr khususnya kepada keluarganya dapat menjadi model untuk pendidikan adab saat ini. Agar lebih mudah dipahami, konsep pendidikan adab penuntut ilmu menurut lbn Abd al-Barr, perlu ditelusuri dari realisasi konsep beliau sendiri yang dimulai dari pendidikan di dalam kehidupan keluarganya.

Tradisi ilmu para ulama dalam kehidupan keluarga menerapkan pendidikan sejak dini sebagai pengamalan dari Q.S. at-Tahrīm [66] ayat 6 yang memerintahkan untuk menjaga mereka dengan cara mendidik dan mengajari adab. Pen-tahqīq alIstidzkār, Abd al-Mu'thi Amīn Qal'ajī, menceritakan kehidupan Ibn Abd al-Barr (1993: jilid 1, 18) dalam mendidik keluarganya. Meskipun beliau tidak mendapati lembaran-lembaran referensi secara khusus yang menceritakan putraputri Ibn Abd al-Barr, khususnya Umar yang menjadi nama kunyah beliau, ada pula yang diberi nama Abdullah Abu Muhammad Ibn Abd al-Barr, dan 
putrinya Zaenab. Menurut Abd alMu'thi, Abdullah telah tumbuh terdidik dengan baik sehingga menjadi seorang ahli adab yang mahir, ahli balaghah yang mengagumkan, terdepan dalam ilmu dan kecerdasan. Kemudian hari ia pun menjadi seorang hakim (qadhì). Beliau tinggal di Isybiliyyah (Cevillia) pada masa al-Mu'tadid Ibn Abbād.

Zaenab, putri tercinta menjadi wanita shalehah sekaligus ulama di kalangan mereka yang mendapatkan ijazah dari ayahnya setelah menulis karya ilmiah dengan baik. la telah menikah di Valensia dengan Muhammad Ibn Muhammad Ibn Alī alLakhamī dan dikaruniai seorang anak $(443$ H.) bernama Abdullah. Selanjutnya, Ibn Abd al-Barr memberi ijazah kepada cucunya pada tahun 462 H. Di saat usianya muda belia (Ibn Abd al-Barr (1993: jilid 1, 20)).

\section{Relevansi Pendidikan Adab} Penuntut Ilmu Menurut lbn Abd Al-Barr dengan Pendidikan Nasional Ibn Abd al-Barr berpendapat bahwa ilmu itu tidak boleh disembunyikan. Meskipun ilmu yang beliau maksud adalah ilmu syari, tetapi jika dikaitkan dengan peraturan Dikti saat ini (Pasal 54 UU. No. 12 Tahun
2012 Tentang Pendidikan Tinggi (UU Dikti), Standar Pendidikan Tinggi (Standar Dikti)), mahasiswa yang telah menyelesaikan penelitiannya terkena kewajiban mempublikasikan hasil penelitiannya itu. Bisa jadi hasil penelitian tersebut menjadi ilmu yang bermanfaat bagi peneliti berikutnya, atau barangkali minimal menjadi informasi yang bermanfaat bagi masyarakat.

Adapun kewajiban menuntut ilmu, tentu sangat relevan pula dengan program pemerintah tentang wajib belajar sembilan tahun (UU Sisdiknas no 20 tahun 2003, Bab I, pasal 1, no. 26). Menurut H.M. Zaenuddin (2008: 1), "Pendidikan merupakan sarana strategis untuk meningkatkan kualitas suatu bangsa. Oleh karenanya kemajuan suatu bangsa dapat ditandai dan diukur dari kemajuan pendidikannya. Kemajuan beberapa negara di dunia ini tidak terlepas dari kemajuan yang dimulai dan dicapai dari pendidikannya”.

Satu hal yang menarik pula, pandangan beliau tentang pendidikan gratis. Dua tahun terakhir pemerintah telah mengalokasikan anggaran untuk pendidikan sebesar $20 \%$ dari APBN. Setidaknya sudah ada upaya untuk meningkatkan pendidikan dengan 
alokasi dana di atas. Jika dibandingkan dengan data tahun-tahun sebelumnya (Agus Irianto: 2011, 84): tahun 1995/1996 mencapai $13,8 \%$, tahun 2000 turun menjadi $5,6 \%$, turun kembali di tahun 2001 menjadi 3,8\%. Pertambahan anggaran di atas tentu mempengaruhi peran pemerintah dalam upaya memberikan pendidikan gratis kepada masyarakat.

Ibn Abd al-Barr mengingatkan agar para pendidik bersikap ilmiah dalam bidang ilmu yang diajarkannya. la tidak bermudah-mudahan dalam menyampaikan ilmu yang diajarkannya sebelum ditelitinya kembali secara ilmiah. Demikian pula dalam dunia ilmu pengetahuan saat ini, bahkan pemerintah memiliki lembaga-lembaga litbang untuk pengembangan ilmiah di berbagai bidang disiplin ilmu. Beberapa tahun terakhir, pemerintah mengadakan program sertifikasi untuk para guru (Permendiknas No. 18 Tahun 2007). Ini merupakan salah satu upaya peningkatan bobot ilmiah pendidikan yang dimulai dari guru-guru yang kompeten dibidangnya. Oleh karena itu, lahirlah Undang-Undang Guru dan Dosen yang mengatur kriteria para pendidik tersebut (UU RI No. 14 Tahun 2005 tentang Guru dan Dosen).
Soetjipto dan Raflis Kosasi (2009: 2930) menguraikan kode etik profesi keguruan. Keduanya mengutip UU No. 8 Tahun 1974 (khususnya pasal 28) dan pesan dari pidato pembukaan kongres PCRI XIII oleh Basuni sebagai Ketua Umum PGRI.

Ibn Abd al-Barr berupaya menanamkan pendidikan adab dengan sentuhan (pendidikan) jiwa yang menyentuh alam bawah sadar peserta didik atau masyarakat secara umum dengan nasehat-nasehat dari para ulama. Pada masa Dinasti Umawiyah, Sang guru mendidik dengan mengajarkan sya'ir, pidato, kisah-kisah dan silsilah Arab. Demikian pula pada masa khilafah al-Abbasiyah, Ibn alMuqaffa' (w. 142 H./759 M.) menyusun dua karya; Al-Adabu al-Kabīr dan AlAdabu ash-Shaghìr. Keduanya mencakup penjelasan tentang kata-kata hikmah, nasehat, akhlak, dan kelembutan hati (zuhū d). Demikian menurut penjelasan Syurūq Mahbūb (2017).

Relevansinya dengan pendidikan saat ini adalah upaya menumbuhkan karakter yang sedang dikembangkan oleh para praktisi pendidikan dan pemerintah. Anis Baswedan (2017), mantan Mentri Pendidikan (2014-2016), dalam sambutannya selaku Gubernur 
DKI Jakarta pada acara Education Expo ASESI (Asosiasi Sekolah Sunnah Indonesia) ke-5 di TMIl Jakarta pada tanggal 29 Oktober 2017 menyampaikan:

Pendidikan adalah tentang masa depan. Pendidikan adalah tentang menyiapkan generasi baru.

Pendidikan bukanlah membentuk, tapi pendidikan adalah menumbuhkan.. Karena ia menumbuhkan, maka hal yang fundamental yang dibutuhkan adalah.. tanah yang subur dan juga iklim yang baik. Kalau kita membayangkan anak- anak itu sebagai bibit (biji), maka biji itu.. tidak kelihatan batangnya, tidak kelihatan akarnya, dan tidak kelihatan daunnya karena ia masih biji. Sehebat apapun sebuah biji, maka tidak akan kelihatan semua komponennya. [....] Karena itu, ketika berbicara tentang pendidikan maka bayangkan seperti kita menumbuhkan biji itu. Karena itu saya sering mengatakan jangan gunakan kata membentuk, apalagi kalau akhlak. Akhlak itu ditumbuhkan, karakter itu ditumbuhkan tidak bisa dibentuk. [....]
Berkaitan dengan kurikulum dan mencakup pula evaluasi pendidikan dalam pandangan Ibn Abd al-Barr, beliau menerapkan sistem pendidikan dalam keluarga, pengkaderan da'i dengan mendidiknya dan memberikan ijazah kepada murid-murid setelah diketahui memiliki kemampuan yang terukur. Hal itu terlihat dari strategi yang beliau tempuh dalam proses pendidikan putra-putri serta cucunya yang memiliki kemampuan melahirkan karya tulis ilmiah (Ibn Abd al-Barr: 1993, jilid 1, 18). Dengan demikian, diketahui pula bahwa strategi implemetasi pendidikan adab penuntut ilmu yang disodorkan oleh lbn Abd al-Barr pada saat ini sebagai kelanjutan dari gagasan para tokoh pendidikan nasional seperti yang telah di gagas oleh Zakiah Darajat. Jadi, dapat dikatakan pula bahwa implementasi pendidikan adab ini merupakan pengejawantahan dari konsep pendidikan Zakiah Darajat.

Pendidikan dalam keluarga memang memiliki kekuatan dalam menanamkan nilai-nilai adab dan menumbuhkan karakter anak. Terlalu banyak kisah-kisah klasik yang dapat ditelusuri seperti kisah Imam Ahmad yang memiliki adab yang luar biasa sejak kecil karena pengaruh pendidikan di 
keluarganya. Demikian pula pada kisah Imam Syafi'i kecil dan kisah para ulama lainnya. Abuddin Nata (2005, 427-428) menguraikan padangan Zakiah Darajat yang menyatakan bahwa penanggung jawab pendidikan adalah keluarga, sekolah, dan masyarakat. Ketiganya memiliki tanggung jawab yang sama dalam pendidikan, yang berbeda hanyalah pada titik tekannya saja. Barangkali penjabarannya perlu diuraikan sebagai berkut:

a. Keluarga berperan sebagai pembentuk akhlak dan kepribadian serta menanamkan nilai-nilai agama dalam kehidupan sehari-hari;

b. Selanjutnya sekolah atau guru berperan sebagai pemberi landasan teoritis dan dalil-dalil tentang segala sesuatu yang diperbuat oleh anak, sehingga perbuatan tersebut semakin kokoh tertanam dalam dirinya;

c. Kemudian sekolahlah yang bertugas mengembangkan wawasan dan keterampilan anak didik dengan ilmu pengetahuan yang terus berkembang;

Adapun masyarakat, turut andil dalam memberikan pengawasan, keteladanan, serta pengalaman pada anak didik tentang cara-cara mengamalkan ilmu yang mereka pelajari di sekolah.

\section{Penutup}

Perbaikan sebuah genarasi menuju peradaban yang lebih tinggi harus dibangun di atas pendidikan yang mapan. Pendidikan yang mengarah kepada perubahan skala sikap dan kedewasaan peserta didik. Gagasan konsep Ibn Abd al-Barr dalam pendidikan dan adab penuntut ilmu memberikan sumbangsih kepada dunia Islam dalam membangun karakter manusia yang beradab dan turut membangkitkan kembali semangat kebangkitan Islam di masa kebangkitan Islam di Andalus.

Konsep yang digagas oleh beliau sangat relevan dengan pendidkan nasional yang saat ini sedang gencar menerapkan pendidikan karakter sehingga ada nilai lebih yang diberikan dari konsep Ibn Abd al-Barr ini, yaitu adab Islami yang harus melekat pada generasi bangsa yang sudah memiliki karakter baik. Oleh karena itu, hendaknya pemerintah memberikan peluang kepada lembaga-lembaga riset Islam, baik di dalam maupun luar negeri untuk mengadakan penelitian (research) dalam rangka pencarian format konsep perubahan sebuah peradaban bangsa dan bekerja sama dengan lembagalembaga pengkajian Islam. Kampus- 
Jurnal TAWAZUN Volume 10 No. 2 Juli - Desember 2017

kampus bersinergi melacak format

konsep adab Islami yang nantinya

disodorkan kepada pemerintah untuk

diadakan pengkajian implementatif

(action research) lebih lanjut. 


\section{DAFTAR PUSTAKA}

Abū Lāwī, Amīn, (tt.). Ushūl at-Tabiyah al-Islāmiyah. Riyadh: Dār ath-Thayibah dan Dār lbn al-Jauzi.

Attas, Syed Muhammad Naquib al-. (1993). Islam and Secularism. Kuala Lumpur: ISTAC.

Baswedan, Anis. Sambutan Education EXPO Asesi. [online]. http://youtu.be/NI5pOnjts8, 8 November 2017.

Barr, Yusuf Ibn Abdi Al-. (1409 H.). Adab al-Mujālasā wa Hamdu al-Lisān. Thantha: Dār ash-Shāhābah at-Turats.

. (1414 H./1993 M.). Al-lstidzkār (tahqīq oleh Abd al-Muthi Amīn Qalajī). Kairo: Dār al-Wayi dan Beirut: Dār Qutaibah. jilid 1, jilid 1.

. (1435 H.). Jāmi Bayāni al-llmi wa Fadhlihi. Riyadh: Dār Ibn al-Jauzi. jilid 1.

Dzahabi, Muhammad ibn Ahmad Adz-. (1405 H.). Al-lbar fi Khabari Man Ghabar (Tahqiq oleh Abu Hājir Muhammad as-Saīd ibn Basyūni Zaghlūl). Beirut: Dār al-Kutub al-Ilmiyah, jilid 1.

. (1432 H./2011 M.). Siyar Alami an-Nubalā. Beirut: Muassasah ar-Risālah. jilid 18.

Fauzi, Indra, Mahasiswa Pembunuh Dosen UMSU Dihukum Seumur Hidup. [online]. https:// nasional.tempo.co/read/news/2017/01/31/063841619/ mahasiswapembunuh-dosen-umsu-dihukum-seumur-hidup, 10 Agustus 2017.

Haq, Abd al-. Dua Kubu Mahasiswa UIN Alauddin Makassar Tawuran di Dalam Kampus. [online]. http://regional.kompas.com/read/2017/ 05/15/22001481/2. kubu.mahasiswa.uin.alauddin.makassar.tawuran. di.dalam.kampus. 10 Agustus 2017.

Husaini, Adian. (2012). Pendidikan Islam Membentuk Manusia Berkarakter dan Beradab. Jakarta: Cakrawala Publishing dan Depok: Adabi Press. . (2015). Wajah Peradaban Barat. Jakarta: Gema Insani.

Humaidi. (1410 H.). Judzwah al-Muqtabis fi Tārīkh Ulamā al-Andalusi. Kairo: Dār alKitāb al-Mishri.

Irianto, Agus. (2011). Pendidikan sebagai Investasi dalam Pembangunan Suatu Bangsa. Jakata: Prenada Media. 
Jawaz, Yazīd ibn Abd al-Qadīr. (2012). Menuntut Ilmu Jalan Menuju Surga. Bogor: Pustaka at-Taqwa.

Langgulung, Hasan. (1988). Pendidikan Islam Menghadapi Abad ke-21. Jakarta: alHusna.

Mahbūb, Syurūq, Mafhūm al-Adab, [online], http://mawdoo3.com/ مفهوم_الأدب/ Juli 7 Ju 2017.

Nahlawi, Abdu ar-Rahmān an-. (1406 H./1986 M.). Alām at-Tarbiyyah fi Tārīkh alIslām; Yūsuf ibn Abdi al-Barr al-Qurthubī. (first ed.) Damaskus: Dār al-Fikri.

Nata, Abuddin. (2005). Tokoh-Tokoh Pembaruan Pendidikan Islam di Indonesia. Jakarta: PT Raja Grafindo.

Purbaya, Angling Adhitya, Hendak Tawuran Pakai Senjata Tajam, 2 Anak SD di Semarang Ditangkap Satpam. [online]. https://news.detik.com/berita/d3353926/hendak-tawuran-pakai-senjata-tajam-2-anak-sd-di-semarangditangkap-satpam. 18 April 2017.

Rizqa, Hasanul. Berkas Pelaku Dewasa Kasus Y Belum Lengkap. [online]. http://nasional. republika.co.id/berita/nasional/ hukum/16/06/03/o873 mk361berkas-pelaku-dewasa-kasus-y-belum-lengkap. 10 Agustus 2017.

Suyūthi, Jalāluddin As-. (1428 H./2007 M.). Tārikh al-Khulafā. Kairo: Dār al-Ghad alJadīd.

Undang-Undang RI No. 14 Tahun 2005 tentang Guru dan Dosen.

Undang-Undang Sistem Pendidikan Nasional no. 20 Tahun 2003.

Utsaimīn, Muhammad Ibn Shālih Al-. (1434 H.). Syarhu Hilyati Thālibi al-Ilmi. Qasim: Muassasah asy-Syaikh Muhammad ibn Shālih al-Utsaimīn al-Khairiyah.

Zaenuddin, H.M. (2008). Reformasi Pendidikan. Yogyakarta: Pustaka Pelajar.

Zuhrī, Abū Asybāl Az-. (1414 H.). Muqaddimah Jāmi Bayāni al-Ilmi wa Fadhlihi. Riyadh: Dār Ibn al-Jauzi.

- (1416 H./1996 M.). Shahīh Jāmiu Bayān al-llmi wa Fadhlihi. Kairo: Maktabah Ibn Taimiyah. 